\section{Review on Forest Carbon Stock and Suggestion for Carbon Release in Ethiopia}

Melese Worku* and Habtamu Agonafir

Faculty of Agriculture and Environmental Sciences, Deber Tabor University, Deber Tabor, Ethiopia

*Corresponding author: Melese Worku, Faculty of Agriculture and Environmental Sciences, Deber Tabor University, Deber Tabor, Ethiopia, Tel: +251 913-986518; Email: Melese1980@gmail.com

Received date: October 30, 2017; Accepted date: November 06, 2017; Published date: November 10, 2017

Copyright: () 2017 Worku M, et al. This is an open-access article distributed under the terms of the Creative Commons Attribution License, which permits unrestricted use, distribution, and reproduction in any medium, provided the original author and source are credited.

\begin{abstract}
The Earth's climate has always gone through periods of change. Over the past few decades, however, the implications of increasing fluctuations in weather patterns have led to recognition of the need for international action. The manmade greenhouse effect is caused by the addition of Greenhouse Gases (GHGs), especially Carbon dioxide $\left(\mathrm{CO}_{2}\right)$, which are emitted when fossil fuels, such as petroleum, coal and natural gas, are burned. In addition to $\mathrm{CO}_{2}, \mathrm{GHGs}$ include Methane $\left(\mathrm{CH}_{4}\right)$, Nitrous oxide $\left(\mathrm{N}_{2} \mathrm{O}\right)$, Hydrofluoric Carbons (HFCs), Per Fluorocarbons (PFCs), and Sulphur hexafluoride $\left(\mathrm{SF}_{2}\right)$. This situation, combined with additional human activities that have decreased the Earth's natural ability to absorb Carbon dioxide such as the depletion of forest cover. Woodland requisition and stock up additional carbon than some other worldly bionetwork and are a significant accepted brake pedal on type of weather alter. This is complete through the development of foliage enlargement and consequential natural carbon appropriation. The forest ecosystem is an important carbon sink and source containing majority of the above ground terrestrial organic carbon. The forest is declining due to human activities. Sustainable management strategies are necessary to make this forest as carbon sink rather than source. To review the forest's carbon foundation possible, dried out biomass is enumerate since $50 \%$ of its division is carbon. Thus, undertaking different studies considering such issues have paramount importance for carbon do business, type of weather alter alleviation and finance magnetism. As a result, increasing home-grown knowledge for biodiversity management, weather modify alleviation and city greening choice is extremely significant in pretty carbon confiscation potentials.
\end{abstract}

Keywords: Forests sequester; HFCs; PFCs

\section{Introduction}

The major carbon pools in hot forest ecosystem are the livelihood biomass of plants and understory vegetation and the departed mass of waste, forested remains and soil natural matter. The carbon store in the airborne income biomass of vegetation is characteristically the major pool and the nearly everyone in a straight line impacted by deforestation and dreadful conditions. Supplementary dominantly the shock of deforestation is the principal donor of steamy terra firma bring into play emission [1,2], with Africa causal 25-30\% of humid land defrayal on or after deforestation, and as a great deal as $0.37 \mathrm{Pg} \mathrm{C}$ $\mathrm{yr}^{-1}$, in the preceding decades [3]. Plummeting release from deforestation and woodland squalor (REDD) is documented as a talented alternative to ease the conservatory effect [4] and REDD is at the present included into the worldwide deliberations procedure. Though on the increase countries are intensely deficient information on carbon supply potentials, the implementation of the REDD is really necessitate estimate on the crash of forest squalor and deforestation on carbon $(\mathrm{C})$ stocks, identifying baselines and monitor forest.

Motionless if the smallest amount predicted increase take place, it was larger than any century-long trend in the last 10,000 years. The principal reason for the mounting thermometer is a century and a half of industrialization: the aflame of ever-greater quantity of oil, gasoline, and coal, the critical of forest, and the put into put into live out of certain farming methods. These behaviors have increased the amount of "school of the arts gases" in the atmosphere, especially Carbon dioxide, Methane, and Nitrous oxide. Such gases occur of course they are critical for life on earth, they keep some of the sun's warmth from reflecting flipside into space, and with no them the planet would be a freezing and barren place. But in greater than before and everincreasing quantity, they are near enough the global warmth to artificially high levels and altering the climate.

Concern about worldwide warm has resulted in study of innovation methods that can be used for ameliorating greenhouse gas effect [5-7]. On or after that method carbon confiscation is one of the most important international focuses [6]. Carbon confiscation is defined as the process or mechanism of capturing and securely storing Carbon dioxide (greenhouse gas) on or after the atmosphere [5]. There are figures of technique under examination for confiscate carbon from the atmosphere. These include ocean sequestration where-by carbon is stored in the oceans through direct injection or fertilization, geologic sequestration in which natural pore spaces in geologic formations serve as reservoirs for long-term Carbon dioxide storage, and earthly sequestration where by a large amount of carbon is stored in soil and vegetation [5].

From earthly impounding forests engage in recreation a significant task in the global carbon cycle [8]. It appropriate and provesions additional carbon than whichever other worldly ecosystem and are an important natural 'brake' on typical weather conditions change [9-12]. Their sequential carbon dynamics are distinguish by stretched stage of steady build-up of biomass (a sink), alternated with little epoch of considerable biomass loss [13]. For this reason, the UNFCC and its Kyoto Protocol familiar the location of forests in carbon confiscation. Purposely, Article 3.3 and 3.4 of the Kyoto Protocol shooting out forest as credible carbon storage [14] though population approximating 
Ethiopia which have distinct probable property are not yet make out carbon supply data's for dissimilar promising neighborhood.

\section{Review of the Related Literature}

\section{Overview of climate change and its cause}

The fast increase in worldwide warmth $\left(0.3-0.6^{\circ} \mathrm{C}\right.$ over the last 100 years and a predictable $1.4-5.8^{\circ} \mathrm{C}$ over the subsequently 100 years) is predictable to make obvious the technique to area and comprehensive changes in climate that could have central shock on human organism and expected systems. A large understanding of the empirical lukewarm of the earth's surface is believed to be due to greater than before concentration of 'greenhouse gases' in the earth's ambiance, which have altered the earth's radiative balance, i.e., the 'greenhouse effect' [14]. The major greenhouse gases are Carbon dioxide $\left(\mathrm{CO}_{2}\right)$, Methane $\left(\mathrm{CH}_{4}\right)$, and Nitrous oxide $\left(\mathrm{N}_{2} \mathrm{O}\right)$, of which $\mathrm{CO}_{2}$ is by far the most important (secretarial for 65 percent of the greenhouse effect). Most of the $\mathrm{CO}_{2}$ emissions derived from human activity are the consequence of remnant fuel burning ( $76 \%$ of the total). Steamy deforestation and forest degradation explanation for a predictable $23 \%$ and the remaining $1 \%$ comes from cement manufacture [15].

The greatest gains in reducing $\mathrm{CO}_{2}$ emission, therefore, can come up to from scheming the smoldering of remnant fuel. However, since forest (as both source and sink of $\mathrm{CO}_{2}$ ) can both add to and mitigate type of weather modify, they are incredibly momentous in strategy to lecture to this complicatedness for the motive that forests can slow at the rear global warm by storing carbon. Various forestry-based strategy (Afforestation/ reforestation and reduced deforestation) are being implemented around the globe for the purpose of offsetting $\mathrm{CO}_{2}$ emissions. Climate change impacts will affect everyone, particularly developing county situated in the sub-Saharan Africa, where countries are already vulnerable to climate variability and have the least capacity to respond [14].

\section{Carbon sequestration: why and what is it?}

Carbon confiscation is the hold prisoner and secures storage of carbon that would otherwise be want only emitted to or remain in the atmosphere and improve the greenhouse consequence process. Clearly define terrestrial carbon appropriation unique it from other carbon sequestration potentials. Terrestrial ecosystem store substantial amounts of fixed cellulose and lignin in a more readily in working condition form (wood). Brown, reports that biomass of forest provides approximation of carbon pool for the reason that about $50 \%$ of the pool is carbon. Wood whose most important constituent is carbon in adding reciprocally acts as a storage tank for water, nutrients and carbohydrates [16]. The development of wood formation therefore, improves the carbon steadiness with respect to respiratory $\mathrm{CO}_{2}$ loss when compare with herbaceous (mostly grasses and forbs) plants on a relative scale.

Tree Resources exterior forest may also incontestably and by a long way contribute to the net $\mathrm{CO}_{2}$ reduction in the atmosphere if promote and lend a hand verify comprehensive warm. Apart from sequestering carbon, mounting material carbon pool sizes also provides additional benefits such as these: stabilize the hydrological rotation and humanizing land individuality such as soil untreated issue from increased a forestation, slowing or stop the trouncing of presented forests, thus protect their carbon reservoir [16], decorative countryside sceneries-adding to the planet's vegetative cover through reforestation thus enlarge living possible carbon reserves, rising the carbon store in artificial treasury, together with wood foodstuffs; civilizing air quality and micro background, and provision of service by this means humanizing the livelihood of numerous citizens in particular in pastoral district.

\section{Carbon allocation in woody plants (trees and shrubs)}

According to Phat [17], firewood is comprised of four primary materials specifically: fiber secretarial for $50 \%$ or supplementary of the immensity; hemi-cellulose-20\%; lignin-25\% and resin or oils secretarial for the remnants. According to Brown [16], reports, carbon quantities are about $50 \%$ of the above ground woody biomass weight. Woody vegetation is characterized by non-respiring biomass. This leads to the augment in girth of a plant due to the on the side meristem action of the vascular cambium produce the secondary xylem popularly known as wood. This dry matter remains an integral part of an individual tree essential to its functioning. As Malhi and Grace [9] writes, plant tissues vary in their carbon storage with stems and fruits have supplementary carbon per gram of dry heaviness than plant life and that longer-lived trees with high-density wood lay up more carbon per size than short-lived, low-density, fast-growing ones.

\section{Carbon sequestration potential of forests}

Tree-plant can act as go under the outside from side to side the course of action of trees enlargement and resulting organic carbon appropriation. Thus, better than ever the quantity of foliage can potentially unhurried the accretion of impressive carbon [10-12,14]. According to IPCC [8], its necessities are about $80 \%$ of all airborne and $40 \%$ of all below-ground earthly organic carbon. For the era of productive season, Carbon dioxide from the atmosphere is taken up by vegetation and stored as plant biomass. On the other hand, at what time forest are empty or tainted, their stored carbon is on the rampage into the mood as Carbon dioxide [11,12].

Tropical deforestation is predictable to emit about 1-2 billion tons of carbon per year throughout the 1990s, which is approximately corresponding to $15-25 \%$ of twelve-monthly international greenhouse chatter emission [9-12]. This indicate instability in the forest due to natural and human influences lead to more carbon released into the atmosphere than the amount used by vegetation during photosynthesis [14]. To combat these circumstances, sustainable management strategies are therefore necessary to make the forest act as a carbon sink rather than source. Currently, the biosphere constitutes a carbon sink that absorbs about 2.3 giga tone of carbon per year, which represents about $30 \%$ of fossil-fuel emissions [5].

As wide-ranging investigational make inquiries has made known, the escalating distinctive $\mathrm{CO}_{2}$ awareness inspire the development of photosynthesis and as a result deposit augmentation. The area of this encouragement show a discrepancy according to poles apart estimates, being superior for wooded area (up to 60\%) and less important for grazing ground and crop (about 14\%). In progress methodical confirmation put it to somebody that supervise and full-grown old enlargement forest act as vigorous carbon sink, sequester carbon at rates of up to 6 tha $^{-1}$ year $^{-1}$ (for boreal and balmy forest) [9-12].

\section{Carbon sequestration measuring methods}

Carbon in Above Ground Biomass (CAGB): The AGB carbon pool consists of each one living undergrowth higher than the loam, comprehensive of stem, stump, brushwood, bark, seed and foliage. The 
AGB accounting is broadly divided into that in trees and that in the understory. The most comprehensive method to establish the biomass of this carbon pool is destructive sampling, where by vegetation is harvested, dried to a standardized accretion and the dry-to-wet biomass ratio well-known. Destructive case in point of trees, on the other hand over, is both well-appointed and somewhat counterproductive in the construction of promote carbon appropriation [18].

Two additional approaches for estimating the biomass compactness of tree and biomass continue source of revenue are more regularly functional. The primary in a straight line estimate biomass compactness from beginning to end biomass weakening equations. The following convert's lumber size estimates to biomass concentration using biomass development factors [16]; everyplace stand tables of all trees in a meticulous diameter group of pupils are available; the biomass per normal tree of each width class of the stand table can be probable through biomass falling off equations, also identify allometric equations. On the other hand, the results of straight illustration of tree diameter in the area of interest can be used in these regression equations. The occupied quantity biomass of the wooded area stand is then derived from the average tree biomass multiplied by the figure of trees in the class, summed across all classes. In both sultry and temperate forest, such length capacities give details more than $95 \%$ of the dissimilarity in tree biomass [14].

There are a figure of database and magazine that in attendance nonpayment weakening equations, stratified by rainfall government and section $[16,19,20]$. These failures to pay equations, based on a huge sample of vegetation, are frequently practical as the age group of confined allometric equations is over and over again not reasonable. On the other hand, the submission of non-attendance equations will have a propensity to trim down the precision of the biomass guesstimate. For instance, precipitation guide by and large apply to plain state of relationships. On the other hand, as distance from the earth increase possible Evapotranspiration decrease and the woodland is wetter at a prearranged rainfall: thus a waning equation functional to highland forest possibly will give in accurate biomass estimates [16,21]. Anywhere in sequence on the amount of wood stockpile exist: such as from marketable inventory, biomass compression can be estimated by escalating the merchantable degree of hoard, net annual increment or wood removals, to account for biomass of the other above-ground machinery. To do this, either Biomass Expansion Factors (BEFs) or Biomass change and development factors are purposeful. BEFs make bigger dry wood stock amount to enlightenment for other, nonmerchantable, machinery of the tree. To establish biomass the volume must also be converted to a weight by multiplication of the wood density as well as the BEF. In contrast, BCEFs used only a single reproduction to transform volume into biomass; this is no-nonsense anywhere wood density are not available. Default BEFs and BCEFs reported in the journalism can be functional in forest carbon secretarial. However, unless in the neighborhood unambiguous equations exist to translate direct measurements of tree height and diameter to volume, deterioration equations to unswervingly guesstimate biomass beginning tree amount lengthwise are preferable [21].

Carbon in Below Ground Biomass (CBGB): The BGB carbon puddle consists of the biomass restricted within live ancestry. As with AGB, even though less data exist, failure equations from root biomass data have been formulate which envisage root biomass base on airborne biomass carbon [14,22]. According to 160 studies, review by Cairns et al. [22] casing humid, mild and boreal forest and find a stand for root-to-shoot ratio of 0.26 , range sandwich sandwiched between 0.18 and 0.30 . Still although relations trees are supposed to, depends on type of weather and soil distinctiveness [23]. Learn conduct by Cairns et al. [22] originate that root-to-shoot ratios were stable amid freedom (hot, mild and boreal), soil feel (fine, medium and coarse), and treetype (angiosperm and gymnosperm).

As with AGB, the requests of default root-to-shoot ratios represent a swap over among expenses of time, possessions and exactness. BGB can also be assess locally by taking soil cores from which roots are extracted; the oven dry weight of these roots can be related to the cross-sectional area of the illustration, and so to the BGB on a for each constituency early point [24].

Carbon in dead litter: The DOM waste carbon pool includes all non-living biomass with a size greater than the limit for Soil Organic Matter (SOM), commonly $2 \mathrm{~mm}$, and less important than that of DOM wood, $10 \mathrm{~cm}$ diameter [25]. This pool encompasses biomass in an assortment of states of decay prior to complete breakup and putrefaction wherever it is distorted to SOM [19]. Local estimation of the DOM litter pool more an extra time relies on the establishment of the wet-to-dry mass ratio. Where on earth this is not convincing default values are easy to get to by wooded area type and climate government from IPCC range from 2.1 tons of carbon per hectare in tropical forest to 39 tons of carbon per hectare in moist boreal broadleaf forest $[19,25]$.

Soil carbon: Soil carbon includes carbon in both stone and whole matter is a key reserve of worldly carbon. Non-living forms of carbon are also bringing hooked on being in soils in outward appearance of carbonate natural resources. On the other hand over, wooded area administration has superior impact on unprocessed carbon and so in untreated carbon collision are for the most part unaccounted [25].

Soil carbon is a significant determinant of site fruitfulness due to its role in maintaining soil corporal and substance property such as comprehensive immovability, cation switch over and water investment capability [26]. Soil stores 2 or 3 period more carbon than that which exists in the idea as $\mathrm{CO}_{2}$ and 2.5 to 3.0 times as much as that store in plants in the earthly natural balance. Land-use and soil-management practice can significantly pressure Soil Organic Carbon (SOC) dynamics and carbon flux on or after the soil. Spatially disseminated estimate of SOC pools and flux are vital necessities for thoughtful the responsibility of soils in the worldwide carbon cycle and for assess likely biosphere answer to climatic revolutionize or variation [27].

\section{Biomass, carbon pools and stock accounting}

Wooded area biomass is unrefined substance resulting from primary production from beginning to end photosynthesis deficiency expenditure through respiration and harvest. Assessment of biomass provides in sequence on the construction and practical characteristic of an afforest and is second-hand to estimate the magnitude of trudge, coal and food machinery [16]. Carbon is nowhere to be found to the atmosphere as $\mathrm{CO}_{2}$. To renovate carbon in biomass to $\mathrm{CO}_{2}$, the tons of carbon are reproducing by the relative amount of the molecular weight of Carbon dioxide to the atomic substance of carbon (44/12). Estimate the biomass firmness of forest thing amabob is, consequently, the leading footstep in jungle carbon clerical.

Carbon pool are workings of the environmental unit that can what's more draw together or leave go of carbon and contain characteristically be split into five main categories: living AGB, living BGB, DOM in wood, DOM in litter and SOM. The categorization of 
carbon pool is not severe and it is not the numeral of category that is significant other than their entirety; pools must not be double-counted and earth-shattering pools be supposed to not be disqualified. With Harvested Wood Products (HWPs) more and more conventional as an accompanying and potentially key carbon pool which exists outer outside of traditional forest boundaries, many carbon pool classifications are being adapted to also embrace HWPs.

A carbon starting lay is a carbon pool from which more carbon flow out than flows in: forests can often represent a net source (rather than go under the surface) of carbon due to the processes of decay, burning and respiration. A carbon sink is a carbon pool from which more carbon flows in than out: forests can act as sink through the process of tree growth and resultant biological carbon sequestration (Brown, 2002). Forests can button sandwiched between organisms a starting place and a sink of carbon in excess of occasion, with the stock of the forest referring to the absolute extent of carbon detained within a jungle component at a specified time.

Stock accounting sums carbon pools on its own point in time. Decisions on which carbon pools should be included are for the most part reliant on the availability of existing data, costs of dimension and the level of conservativeness requisite [24]. Trees often correspond to the furthermost division of full amount biomass of a forested area, with other carbon pools no more than a division of the total tree biomass. The understory is expected to be equivalent to $3 \%$ of above-ground tree biomass, lifeless wood 5-40\%, and fine waste only $5 \%$ of that in the above-ground tree biomass. BGB is more changeable, ranging between $4-23 \%$, and can be more than two times greater than that in the AGB tree [16]. AGB in trees also responds more rapidly and significantly as a result of land-use change than other carbon pools. As a consequence, the majority of carbons accounting efforts are focused on tree AGB, for which there is a substantial forest science research base.

\section{Carbon accounting and types}

In 1946, the Food and Agriculture Organization (FAO) established the Forest Resource Assessment (FRA) which, published every five to ten years, compiles data gathered through national statistics and country-level reporting processes. Although criticized [12], the FRA still provides the most comprehensive assessment of global forest cover, management and trends to date. In combination with the substantial body of forest science research literature, the FRA and similar forest inventories provide the background for carbon accounting.

The forestry sector plays a vital role in the global balance of GHGs. Deforestation alone accounts for approximately $20 \%$ of anthropogenic emissions $[28,29]$ and the forestry sector represents upwards of $50 \%$ of global greenhouse gas mitigation potential [6]. As forests rise up the climate change agenda, three types of forest carbon accounting have developed: stock accounting, emissions accounting and project emission reductions accounting.

Stock accounting: Forest carbon stock accounting often forms a starting point for emissions and project-level accounting. Establishing the terrestrial carbon stock of a territory and average carbon stocks for particular land uses, stock accounting allows carbon-dense areas to be prioritized in regional land use planning. An early form of forest carbon accounting, emissions and emission reductions accounting have evolved from the principles established for stock accounting [30].

Emissions accounting: Production secretarial is essential to charge the weighing machine of emissions on or subsequent to the forestry subdivision family member to other sector. It also aids with both feet on the floor goal-setting for GHG production target. Underneath the United Nations Framework meeting on typical weather modify (UNFCCC) and the Kyoto Protocol, countries are mandated to undertake some land use, land use change and forestry (LULUCF) carbon secretarial. With a significant portion of developing country emission arise on or behind the LULUCF sector, the forestry division is likely to connect in free time a famous location in climate modify strategies in these countries.

Project emission reductions accounting: Carbon secretarial for forestry development emission reduction is obligatory for both projects undertake under the bendable means of the Kyoto Protocol and the voluntary carbon markets. In cooperation require first-rate carbon accounting to ensure that emissions reductions are real, undying and demonstrable. For project to manufacture tradable emanation reductions, accounting methods between countries, regions and projects must be uniform in both urbanized and developing countries [31]. What went before forest inventory and research outputs provide a substantial source of information on forest biomass characteristics. The challenge is to interpret this in succession into carbon approximation, in meticulous increasing the coverage and/or scaling up make inquiries that in surfeit of and over another time focus on environmental zones or detailed territories. Ultimately, the character of forest carbon estimates were govern by a numeral of factor, not smallest amount instant in moment in time and monetary reserve restraint. acknowledge so as to trade-offs between factors in the secretarial procedure are foreseeable, the carbon secretarial process must stick on to first-rate live out administration if forestry is to be adopt more generally in typical weather transform guiding principle [30].

\section{Principles of forest carbon accounting}

Accounting good practice: In spite of the kind of office store, emissions or development release reductions- there are a digit of major perspective for carbon office that should be follow devotion to good practice promotes better thoughtful, authority and faith in the secretarial organization, which is serious for both political and public reception [30]. Although publication generally discusses 'carbon' secretarial, completeness calls for the enclosure of other relevant GHGs in emissions and project emission reductions secretarial. Thus, carbon accounting often refers to accounting of Carbon dioxide equivalent $\left(\mathrm{CO}_{2} \mathrm{e}\right)$, a metric which allows standardization of the six major GHGs based on their global warming potential. In the forestry sector, management regimes influence the scale of Methane $\left(\mathrm{CH}_{4}\right)$ and Nitrous oxide $\left(\mathrm{N}_{2} \mathrm{O}\right)$ emissions in addition to carbon emission. Methane emissions effect from aflame and decomposing of organic matter in oxygen-free atmosphere, such as waterlogged soils. Nitrous oxide is emitting during on fire, rotting of natural substance, soil natural matter mineralization and ground fertilization by nitrogen fertilizers. Although these gases tend to be shaped in lower volumes than $\mathrm{CO}_{2}$ they have greater global warming potential. To adhere to good practice, $\mathrm{CH}_{4}$ and $\mathrm{N}_{2} \mathrm{O}$ emissions should be fully accounted for where noteworthy. However, where minor, meaning less than $1 \%$ of the total [21], such emission can be absent from secretarial.

Carbon accounting tools: Under the UNFCCC, developed realm is grateful to performance carbon secretarial inventories in the land use splitting up, comprehensive of forest. For this grounds and for plan construction reduction clerical, a number of gear and model have be transformed into to be had which produced by countrywide administration, comprehensive union and research institutions, these 
Page 5 of 6

vary in geographical coverage, forest performance and carbon pool incorporated, and the period of aspect obligatory for the depiction parameter.

In urbanized country a numeral of woods carbon secretarial model live. Those models are conflicting as of counter to state. for that reason from the United States: COLE, the Carbon On-Line Estimator, the midpoint for Urban Forest delve into Tree Carbon Calculator (CTCC), FORCARB and the countryside Management System (LMS), starting the 27 United Kingdom: CARBINE, C-Flow and C-Sort. From Europe: the European Forest in sequence Scenario model (EFI-SCEN). On the other hand, these utensils are in the main pertinent only to forests of the nation, or district, in which they contain, been urban and are thus incomplete in request. Other tools which are developed in Canada is applicable over wider geographical areas is CBM-CFS3.

Additional wide forest carbon-inventory models include $\mathrm{CO}_{2}$ FIX and Graz/Oak Ridge Carbon Accounting Model (GORCAM). The version 3 of $\mathrm{CO}_{2}$ FIX has detailed modules for biomass, soil, wood products and bio-energy, as well as modules for finance and carbon accounting. These models take for granted comparatively homogenous forest stand inside conditions of plant life arrangement, growth dynamics and species work of art. GORCAM, also a stand-level accounting model, consider change of carbon in biomass, lessening of carbon emission due to replacement of remainder fuel otherwise energy-intensive capital, carbon store in timber manufacture, and the recycle and ablaze of fritter away wood [32].

More multipart models, in which growth is driven by suggest photosynthesis, also continue livelihood for instance CENTURY, which simulate carbon, nutrient and water dynamics for ecosystems; Physiological main beliefs Predict Growth (3PG); and BioGeochemical Cycles (BIOME-BGC), which simulate net most significant output for manifold biomass pool. However, the ingredient of parameter compulsory set for that these models are best suited to exceptionally small scale accounting applications.

Additional model have evolve only for forest development carbon secretarial, AR in particular. TARAM, developed by the Bio-Carbon Fund of the World Bank and the Forma Project, for example, assists in the application of AR methodologies accepted for use in CDM project. atmosphere and assemblage of people based building for manipulative a forestation, reforestation and re-vegetation scheme in the CDM (ENCOFOR), urbanized by the World Agro forestry Centre, is alike in aim, but has the complementary thing of make the a large amount of surroundings and local reimbursement in increasing country.

There is a worldwide and district level information valuable for forest carbon secretarial. International land-use and land envelop datasets exist, for the most part on or after remote sensing imagery, although image declaration and the exactness of ground-referenced data are usually incomplete. Source of data take in global specialist, worldwide organization publishing figures, such as the United Nations and OECD, and global technological journal. In meticulous, the FAO Forest Resources Assessment, the IPCC Agriculture, Forestry and Other Land Use (AFOLU) inventory organization quantity [25], and FAO's primer for estimate biomass [16] all provide parameter information that can be used in carbon accounting. The IPCC recognizes that trade-offs exist and so present a multi-tiered move toward to emission accounting. Three level of detail with conflicting arithmetical requirement of method, in order requirements and sources of activity data are offered to estimate net emissions.
The majority straight way to enumerate the carbon stored in mid-air living wooded area biomass is to produce all trees in an approved area, dehydrated up them and think about the biomass. While this technique is straightforward for a particular background, it is prohibitively protracted, luxurious, unhelpful and unworkable for country-level examination. No stripe of attack can yet directly establish forest carbon stock across countryside. as a consequence, much attempt has moved out into increasing tools and models that can 'weighing machine up' or extrapolate uncooperative manufacture data points to enhanced weigh mechanism support on proxy on purpose in the field or from remote sense instrument [33]. Generally now-a-days, there are different models developed for carbon sequestration estimation. Thus, Forest Inventory Optical remote sensors, Very highresolution Airborne optical remote sensors, Radar remote Sensors, Laser remote sensors all these methods have their advantages and disadvantages in case of cost, accuracy, and knowledge of using [2].

\section{Overview of the Ethiopian vegetation}

Ethiopia has a diverse topography from deep Rift Valley to highest highlands. Some of these highlands include Chilalo and Kaka Mountains with a height of $4350 \mathrm{~m}$ and $4400 \mathrm{~m}$ above sea level respectively [34]. The vegetation of Ethiopia described and classified based on climate and altitude as the most important factor [15]

In the early approach towards the classification of vegetation has been largely by way of identifying the major physiognomic types to establish geobotanical map of Ethiopia and Somalia [19]. So that lowlands are characterized by steppes, savannas and wood lands, while highlands are characterized by forests. This approach revised by generalizing the smaller units in to such broad zones, having similar approach to establish a scheme of classification. As a result following the suggestion of Beals [35] and FAO [15] the natural vegetation in broad terms classified into seven zones as, afro alpine and sub afroalpine, Dry evergreen Montane forest and associated grasslands, moist evergreen Montane Forests, evergreen Montane woodlands and scrubs, deciduous woodlands, lowland semi-desert vegetation and costal vegetation.

The beautiful and highest highlands of Ethiopia are unique Afroalpine areas with diverse fauna and flora. The Afroalpine region has more than $300,000 \mathrm{~km}^{2}$ of land above 3200 m.a.s.l. and more than $25,000 \mathrm{~km}^{2}$ of land above 3000 m.a.s.l. [15,36]. Besides, their wonderful panorama, these highlands possess attractive and indigenous vegetation. In addition, they are home for endemic species. Yalden [37], estimated that almost $80 \%$ of the land in Africa over 3,000 $\mathrm{m}$ altitude occurs in Ethiopia and speculated that the high rate of endemicity was a result of this very large area of highland.

Bezawork Afework [38], tried to show the close relationship between climate and altitude on the one hand and vegetation on the other classifies the Ethiopian vegetation in one the same way. Based on this, they try to show the Ethiopia agro-ecological zone on highlands. In the high mountain area, plant species diversity is low, and vegetation cover varies from $100 \%$ at the lower end of the altitude range and sheltered areas, to less than $10 \%$ at the highest and most exposed altitudes.

Evergreen Montane forests covered originally an extensive part of Ethiopia plateau. Pressure on the caused by an increase in human and livestock population has produced serious ecological problems. Especially the dry ever green montane forest which characterizes study area, occur scattered in the northern, eastern and southern parts of the 
plateau. This vegetation zone contains the most important species like Juniperusprocera, Oleaafricana, Prunusafricanusand Podocarpusfalcatus. This zone is associated with this montane grassland comprising of species of Hyparrhenia, Andropogon, Chloris and Pennisetum.

\section{Conclusion}

- Bearing in mind such and other distant places for in-situ and exsitu biodiversity management is exceptionally significant and it may be a success jam-packed commotion

- Undertaking poles apart schoolwork which help the safeguarding of anticipated material goods and comprise a collision for carbon buy and sell, type of weather change improvement and sponsor draw is supposed to be empowered.

\section{References}

1. UNFCCC (2012) Guide to Climate Change, Conference of Party. Doha, Qatar.

2. Houghton RA (2003) Revised Estimates of the Annual Net Flux of Carbon to the Atmosphere from Changes in Land Use and Land Management 1850-2000. Tellus 55: 378-390.

3. Defries RS, Houghton RA, Hansen MC, Field CB, Skole D, et al. (2002) Carbon emissions from tropical deforestation and regrowth based on satellite observations for the 1980s and 1990s. Proc Natl Acad Sci. USA 99: 14256-14261.

4. Santilli M, Mouthino P, Schwartzman S, Nepstad D, Curran L, et al. (2005) Tropical Deforestation and the Kyoto Protocol. Clim Change 71: 267-276.

5. Penman J, Kruger D, Galbally I, Hiraishi T, Nyenzi B, et al. (2000) IPCC Good Practice Guidance and Uncertainty Management in National Greenhouse Gas Inventories. Intergovernmental Panel on Climate Change (IPCC), IPCC/OECD/IEA/IGES, Hayama, Japan.

6. Solomon S, Qin D, Manning M, Chen Z, Marquis M, et al. (2007) IPCC Contribution of Working Group I to the Fourth Assessment Report of the Intergovernmental Panel on Climate Change. The Physical Science Basis. Cambridge University Press, Cambridge Jackson, JE Institute of Terrestrial Ecology, Edinburgh, USA, pp. 545-552.

7. Penman J, Gytarsky M, Hiraishi T, Krug T, Kruger D, et al. (2003) Good Practice Guidance for Land Use, Land-Use Change and Forestry: Institute for Global Environmental Strategies.

8. Watson RT and the Core Writing Team (2001) IPCC Climate Change 2001: Synthesis Report. Contribution of Working Groups I, II and III to the Third Assessment Report of the Intergovernmental Panel on Climate Change. Cambridge University Press, Cambridge, UK.

9. Malhi Y, Grace J (2000) Tropical forests and atmospheric carbon dioxide. Trends Ecol Evolut 15: 332-337.

10. Fearnside PM, Laurance WF (2003) Comment on "Determination of Deforestation Rates of the World's Humid Tropical Forests. Science 299: 1015.

11. Fearnside PM, Laurance WF (2004) Tropical Deforestation and Greenhouse Gas Emissions. Ecological Apply 14: 982-986.

12. Houghton RA (2005) Tropical deforestation as a source of greenhouse gas emissions. Tropical Deforestation and Climate Change Mutinho and Schwartzman (Belem: IPAM).

13. Phillips OL, Malhi Y, Higuchi N, Laurance WF, Núñez PV, et al. (1998) Changes in the Carbon Balance of Tropical Forests: Evidence from LongTerm Plots. Science 282: 439-442.

14. Brown S (2002) Measuring carbon in forests: Current status and future challenges. Journal of Environmental Pollution 116: 363-372.
15. FAO (1996) Country Report International Technical Conference on Plant Genetic Resource. June, Germany, pp. 17-23.

16. Brown S (1997) Estimating Biomass and Biomass Change of Tropical Forests: A Primer. FAO Forestry Paper 134, FAO, Rome.

17. Phat NK, Knorr W, Kim S (2004) Appropriate measures for conservation of terrestrial carbon stocks-Analysis of trends of forest management in Southeast Asia. Forest Ecology and Management 191: 283-299.

18. Schroeder P, Brown S, Mo J, Birdsey R, Cieszewski CJ (1997) Biomass Estimation for Temperate Broadleaf Forests of the United States Using Inventory Data. Forest Science 43: 424-434.

19. FAO (1997) Estimating biomass and biomass change of tropical forests: a primer. Rome, Italy: FAO Forestry Paper No.134.

20. Chamshama SAO, Mugasha AG, Zahabu E (2004) Stand Biomass and Volume Estimation for Miombo woodlands at Kitulangalo, Morogoro, Tanzania.

21. IPCC (2003) Good practice guidance for land use, land- use change and forestry. Institute for Global Environmental Strategies (IGES), Hayama.

22. Cairns MA, Brown S, Helmer EH, Baumgardner GA (1997) Root biomass allocation in the world's upland forests. Oecologia 111: 1-11.

23. Brown S, Lugo A (1982) The storage and production of organic matter in tropical forests and their role in the global carbon cycle. Biotropica 14: 161-187.

24. Macdicken K (1997) A Guide to Monitoring Carbon Storage in Forestry and Agroforestry Projects. Winrock International, 1611 N. Kent St., Suite 600, Arlington, VA 22209, USA.

25. Eggleston HS, Buendia L, Miwa K, Ngara T, Tanabe K (2006) IPCC Guidelines for National Greenhouse Gas Inventories. Prepared by the National Greenhouse Gas Inventories Programmed. (Japan: Institute for Global Environmental Strategies).

26. Davidson EA, Trumbore SE, Amudson R (2000) Biogeochemistry: Soil warming and organic carbon content. Nature 408: 789-790.

27. Schimel D, Melillo J, Tian H, McGuire AD, Kicklighter D, et al. (2000) Contribution of Increasing $\mathrm{CO} 2$ and Climate to Carbon Storage by Ecosystems in the United States. Science 287: 2004-2006.

28. FAO (2006) Global Forest Resources Assessment 2005. FAO Forestry Paper, Report number: 147. Rome, FAO.

29. Stern N (2006) The Economics of Climate Change: The Stern Review. Cambridge University Press, Cambridge, UK.

30. Greenhalgh S, Daviet F, Weninger E (2006) The Land Use, Land-Use Change, and Forestry Guidance for Greenhouse Gas Project Accounting. The Greenhouse Gas Protocol, World Resources Institute.

31. Watson C (2007) Forest Carbon Accounting: Overview \& Principles. London School of Economics and Political Science.

32. Marland G, Fruit K, Sedjo R (2001) Accounting for sequestered carbon: the question of permanence. Environmental Science and Policy 4: 259-268.

33. Brown S, Gillespie JR, Lugo AE (1989) Biomass Estimation Methods for Tropical Forests with Application to Forest Inventory Data. For Sci 35: 881-902.

34. Brown LH (1969) Observations on the Status, Habitat and Behavior of Mountain Nyala (Tragelephusbuxtoni) in Ethiopia. Paris.

35. Beals FW (1978) Ethiopia. Actaphysiogeogr Suec 54: 137-140.

36. Yalden DW, Largen MJ (1992) The Endemic Mammals of Ethiopia. Mammal Review 22: 115-150.

37. Yalden DW (1983) The extent of high ground in Ethiopia compared to the rest of Africa. Sinet: Ethiopia. J Sci 6: 35-40.

38. Bogale B, Bekele A, Balakrishnan M (2004) Population Status, Structure and Activity Pattern of the Bohor reedbuck Redunca redunca in the Bale Mountains National Park. M. Sc. Thesis. Addis Ababa University, Ethiopia. 